\title{
What keeps you up at night? Genetics professionals' distressing experiences in patient care
}

\author{
Barbara A. Bernhardt, $M S^{1,2}$, Rachel Silver, ScM ${ }^{3}$, Cynda Hylton Rushton, PhD, RN ${ }^{4,5,6,7}$, \\ Ellyn Micco, $M S c^{8}$, and Gail Geller, ScD, $M H S^{4,5,9,10}$
}

\begin{abstract}
Purpose: To explore specific patient care experiences that genetics professionals associate with distress and the emotions engendered by those experiences. Methods: We conducted semistructured telephone interviews with clinical geneticists, genetic counselors, and genetic nurses that focused on a single distressing experience. Results: Fourteen clinical geneticists, 25 genetic counselors, and 14 nurses were interviewed. We categorized the situations that interviewees associated with distressing patient care experiences into seven major types: patient/ family decisions ( $27 \%$ of total situations), giving bad news $(17 \%)$, colleague behavior (15\%), end-of-life issues $(12 \%)$, unintended outcomes $(12 \%)$, difficult patients $(8 \%)$, and injustice/inhumanity $(8 \%)$. Interviewees reported experiencing a variety of negative emotions during these situations, including anger, guilt, helplessness, and inadequacy. Conclusions: The distress and resulting emotions experienced by genetic service providers must be acknowledged. Interventions are needed to assist the clinician in becoming self-aware by reflecting on experienced emotions, examining belief systems and values, and understanding the connection between their emotions and behavior. Involvement in mindfulness meditation, reflective writing, peer support groups or additional communication skill-based training could address this need. In addition, clinicians should seek ways to increase personal meaning derived from providing patient care. Genet Med 2010:12(5): 289-297.
\end{abstract}

Key Words: burnout, genetic service providers, distress, countertransference, training

T he nature of service provided by genetics professionals, the types of patients they see, and the disorders they deal with may cause genetics professionals considerable distress in the course of caring for individuals and families who have or who are at risk for a genetic disorder. ${ }^{1}$ These patients often are confronting profound personal and emotional life events. Many interactions occur at the time of diagnosis of a serious or

From the ${ }^{1}$ Department of Medicine and ${ }^{2}$ Penn Center for the Integration of Genetic Healthcare Technologies, University of Pennsylvania, Philadelphia, Pennsylvania; ${ }^{3}$ The Prenatal Diagnosis and Medical Genetics Program, Mount Sinai Hospital, Toronto, Canada; ${ }^{4}$ Johns Hopkins Berman Institute of Bioethics; ${ }^{5}$ Department of Pediatrics, Johns Hopkins University School of Medicine; ${ }^{6}$ School of Nursing, Johns Hopkins University; ${ }^{7}$ Harriet Lane Compassionate Care, Johns Hopkins Children Center, Baltimore, Maryland; ${ }^{8}$ Department of Population Science, Fox Chase Cancer Center, Philadelphia, Pennsylvania; ${ }^{9}$ Department of Health, Behavior and Society, Johns Hopkins University Bloomberg School of Public Health; and ${ }^{10}$ Department of Medicine, Johns Hopkins University School of Medicine, Baltimore, Maryland. Barbara Bernhardt, MS, CGC, Hospital of the University of Pennsylvania, Penn Tower, Suite 1115, 3400 Spruce Street, Philadelphia, PA 19104. E-mail: Barbara.bernhardt@uphs.upenn.edu.

Disclosure: The authors declare no conflicts of interest.

Submitted for publication December 17, 2009

Accepted for publication March 1, 2010.

Published online ahead of print April 8, 2010

DOI: $10.1097 /$ GIM.0b013e3181db82d9 life-threatening disorder in a fetus, child or adult. Other interactions occur during the course of providing on-going care to genetically affected individuals, including care rendered near the end of life. Caring for patients with serious or life-threatening conditions is often associated with provider burnout and various types of distress, including a sense of failure and frustration, feelings of powerlessness, and grief. ${ }^{2-5}$

Furthermore, genetic service providers and their patients face a great deal of uncertainty in terms of diagnosis, recurrence risks, and disease severity, and uncertainty is an acknowledged source of stress. ${ }^{2,6}$ In addition, genetics professionals are trained to provide nondirective counseling and often see patients only once; this may necessitate selection of information that has to be presented to patients with whom a relationship has not been developed. All of these characteristics might contribute to distress among genetic service providers.

Much of this distress is not unique to genetic service providers, and some sources of distress, such as caring for patients at the end of life, breaking bad news, and dealing with hateful patients, have received a great deal of attention in the medical and nursing literature. ${ }^{3,7-9}$ One type of distress that is pertinent to clinicians in genetics is moral distress, which was initially conceptualized to address ethical issues arising in nursing care. ${ }^{10}$ Moral distress, as originally described by Jameton, ${ }^{11}$ occurs when a health professional knows, or believes she knows, the ethically appropriate course of action to take but is unable to carry it out because of a variety of possible obstacles. This inability to act often results in anger and frustration, leading to possible compromised integrity and eventually to burnout. ${ }^{12-14}$ The experience of moral distress was initially ascribed in part to the position of nurses in the hierarchy where they have limited authority to act when involved in morally significant relationships with sick or vulnerable patients. ${ }^{15}$ Physicians also experience moral distress when they lack the power to act on the clinical decisions they deem appropriate or when they are forced to balance conscience with professional expectation. ${ }^{15}$

Another type of distress, compassion fatigue, occurs as a result of prolonged exposure to trauma and suffering, leading to a variety of symptoms including avoidance of reminders involved in the event and many psychological and psychosocial symptoms. ${ }^{16}$ Compassion fatigue is more prevalent among clinicians who have more job-related or personal stress and among those who engage in fewer self-care activities. ${ }^{17}$ There is very little known about the extent of compassion fatigue among genetics professionals. Benoit et al. ${ }^{18}$ explored compassion fatigue among a small group of genetic counselors and documented that it is prevalent and related to feeling overwhelmed by deeply caring about patients and by being unable to relieve patient suffering while feeling responsible for what patients must endure. We have previously shown that genetics professionals frequently experience distress from compassion fatigue emanating from patient suffering or from being emotionally attached to a patient. ${ }^{1}$ Others have suggested that countertrans- 
ference, occurring when the provider shares similar experiences, emotions, and stresses with a patient, is a frequent source of distress among genetic providers because of their desire to engage empathically with patients. ${ }^{19}$ Being exposed to patients' suffering may serve as a reminder to the clinician of his or her own past losses or failures, leading to overidentification with the patient, or to emotional distancing.

In addition to compassion fatigue, we showed that genetic service providers experience other types of distress during the course of providing care to patients, and that this distress is significantly related to burnout, job dissatisfaction, and lack of meaning derived from providing patient care. ${ }^{1}$ Through responses from surveyed genetic service providers, we were able to identify eight discrete sources of distress experienced: collegial distrust, personal values conflicts, compassion stress, the burden of professional responsibility, negative patient regard, inauthenticity, concerns about informational bias, and patient dread. ${ }^{1}$ Those sources of distress identified through factor analysis of survey data were not tied to any specific clinical care experiences. In this study, we report on semistructured telephone interviews with a subset of survey respondents that explored specific patient care experiences associated with distress and the emotions they engender.

\section{METHODS}

We conducted semistructured telephone interviews between June and November 2006 with clinical geneticists, genetic counselors, and genetics nurses to elicit perspectives on distress and meaning derived from patient care. Potential interviewees were respondents to a mailed survey relating to distress and meaning among genetic service providers. ${ }^{1,5,20}$ Surveys were mailed to randomly selected members of the National Society of Genetic Counselors, the International Society of Nurses in Genetics, and the American College of Medical Genetics. Surveys were completed by 214 genetic service providers (a 55\% response rate). At the end of the survey, respondents were asked to indicate whether they were willing to participate in a 45- to 60-minute follow-up telephone interview. Those willing to participate in the interview were mailed a consent form and were contacted by phone or email to schedule a phone interview. Participants were considered eligible to be interviewed if they provided any patient care.

A total of 32 genetic counselors, 21 nurses, and 21 geneticists expressed interest in being interviewed, and interviews were completed with 25 genetic counselors ( 20 females and 5 males), 14 nurses (all females), and 14 geneticists ( 8 males and 6 females). Participants reported between 2 and 32 years as a genetic service provider. Participants received \$25 for participating in the interview. The Johns Hopkins Medical Institution Institutional Review Board approved this study.

The interview guide contained open-ended questions with follow-up probes for each question. A portion of the interview asked participants to focus on one patient-care related encounter of their choice that they found to be particularly distressing, something that "kept them up at night." Participants were asked several days before the interview took place to think about this one distressing situation that they would like to discuss. During the interview, participants were asked to describe the situation, explain what was distressing about it, and describe their feelings during and after the situation.

The interview guide was piloted on two of each type of provider to assess face validity of the questions and familiarize interviewers with the interview guide and process. Small changes to the guide were made accordingly, including clarification of certain word choices and question ordering.

Telephone interviews ranged between 30 and 80 minutes in length. Participants were interviewed by one of four trained interviewers. None of the interviewers personally knew any of the individuals they interviewed. Consent forms were collected by mail before interviews were conducted.

Each interview was recorded and transcribed. Transcripts were imported into NVivo 7, a qualitative software package designed to assist in qualitative data analysis. Once all interviews were transcribed, a coding team consisting of two investigators and a research assistant re-read $25 \%$ of the interviews and met to develop a codebook, to identify and discuss specific coding categories. Types of situations precipitating distress and the type of distress experienced were identified, and codes were developed for each. Once codes were established, they were compiled into a codebook, which was then used to code the remaining $75 \%$ of the interviews. As new themes emerged, they were reviewed at regular coding meetings and compared with the representative quotes for preexisting codes. New themes were discussed and assigned either a new or preexisting code on consensus of the coding team.

All coded transcripts were reviewed at regular coding meetings to assess intercoder reliability. When the team disagreed on a code, they discussed the theme until consensus about its meaning was reached and a final code was agreed upon. Intercoder reliability was calculated by agreement average. Reliability was $79 \%$.

Once transcripts were coded, we conducted content analysis to identify the situations associated with distress and the emotions experienced during the distressing situation. Quotes illustrating the various types of situations and sources of distress were highlighted.

\section{RESULTS}

Of the 54 interviewees, 52 were able to remember and discuss a particularly distressing situation. The situations were categorized into seven major types: patient/family decision making, giving bad news, colleague behavior, end of life, unintended outcomes, difficult patients, and social injustice. Table 1 summarizes the frequency of each type of situation according to disciplinary background of the clinician. Table 2 outlines the specific nature of the distress experienced in each situation and the emotion(s) engendered by it. The seven types of distressing situations are subsequently described in detail.

Table 1 Distressing situations discussed

\begin{tabular}{lcccc}
\hline & \multicolumn{4}{c}{ Provider type } \\
\cline { 2 - 5 } Situation type & $\begin{array}{c}\text { Clinical } \\
\text { geneticist }\end{array}$ & $\begin{array}{c}\text { Genetic } \\
\text { counselor }\end{array}$ & Nurse & Total \\
\hline Patient/family decisions & 4 & 5 & 5 & 14 \\
Giving bad news & 2 & 6 & 1 & 9 \\
Colleague behavior & 2 & 2 & 4 & 8 \\
End-of-life & - & 6 & 1 & 7 \\
Unintended outcome & 3 & 2 & 1 & 6 \\
Difficult patient & 2 & 2 & - & 4 \\
Injustice/inhumanity & 1 & 2 & 1 & 4 \\
\hline
\end{tabular}


Table 2 Type of distress and emotional response to distressing situations

\begin{tabular}{|c|c|c|}
\hline Situation & Type of distress & $\begin{array}{c}\text { Emotion } \\
\text { experienced }\end{array}$ \\
\hline \multirow{5}{*}{$\begin{array}{l}\text { Patient/family } \\
\text { decision making }\end{array}$} & Personal values conflicts & Guilt \\
\hline & $\begin{array}{l}\text { Burden of professional } \\
\text { responsibility }\end{array}$ & Anger \\
\hline & Inauthenticity & Confusion \\
\hline & $\begin{array}{l}\text { Concern about } \\
\text { informational bias }\end{array}$ & Inadequacy \\
\hline & Negative patient regard & Helplessness \\
\hline \multirow[t]{6}{*}{$\begin{array}{l}\text { Giving bad } \\
\text { news }\end{array}$} & $\begin{array}{l}\text { Burden of professional } \\
\text { responsibility }\end{array}$ & Helplessness \\
\hline & $\begin{array}{l}\text { Concern about } \\
\text { informational bias }\end{array}$ & Inadequacy \\
\hline & Compassion stress & Grief \\
\hline & Patient dread & Apprehension \\
\hline & & Rejection \\
\hline & & Guilt \\
\hline \multirow{5}{*}{$\begin{array}{l}\text { Colleague } \\
\text { behavior }\end{array}$} & Collegial distrust & Abandonment \\
\hline & $\begin{array}{l}\text { Burden of professional } \\
\text { responsibility }\end{array}$ & Disrespected \\
\hline & Personal values conflicts & Helplessness \\
\hline & & Anger \\
\hline & & Resentment \\
\hline \multirow[t]{6}{*}{ End-of-life } & Compassion stress & Helplessness \\
\hline & Burden of professional & Inadequacy \\
\hline & & Grief \\
\hline & & Apprehension \\
\hline & & Guilt \\
\hline & & Embarrassment \\
\hline \multirow[t]{6}{*}{$\begin{array}{r}\text { Unintended } \\
\text { outcomes }\end{array}$} & $\begin{array}{l}\text { Burden of professional } \\
\text { responsibility }\end{array}$ & Inadequacy \\
\hline & Patient dread & Guilt \\
\hline & & Helplessness \\
\hline & & Abandonment \\
\hline & & Humiliation \\
\hline & & Shame \\
\hline \multirow{7}{*}{$\begin{array}{l}\text { Difficult } \\
\text { patient }\end{array}$} & Negative patient regard & Anger \\
\hline & Patient dread & Guilt \\
\hline & Personal values conflicts & Manipulation \\
\hline & & Resentment \\
\hline & & Shame \\
\hline & & Frustration \\
\hline & & Inadequacy \\
\hline \multirow{4}{*}{$\begin{array}{l}\text { Social } \\
\quad \text { injustice }\end{array}$} & Compassion stress & Horror \\
\hline & & Outrage \\
\hline & & Guilt \\
\hline & & Frustration \\
\hline
\end{tabular}

\section{Patient/family decisions ( $27 \%$ of total)}

The most frequent type of distressing situation involved decision making by patients and/or family members, usually surrounding pregnancy terminations, treatment or management options, or genetic testing. The distress associated with these situations frequently stemmed from values conflicts between the provider and the patient. Values conflicts would occasionally interfere with partnering with a patient. Here, a genetic counselor discusses her experience with a patient who does not place the same value on an empowered and equal place for women in a relationship.

"The pregnant patient in this case really lets the partner, who is more assertive or in some cases, even aggressive, call the shots and sort of takes her own opinion and puts it to the side in favor of the partner's opinion. Those are the circumstances that personally, I find hard to understand." (Genetic counselor)

Many interviewees valued information, especially genetic information that could have implications for family members and were upset when patients did not seek out genetic testing. One genetic counselor described the conflict this way:

"I am on that side of the camp of 'who wants to know.' It is hard for me when there are people with their head in the sand, who don't want to know the information." (Genetic counselor)

In another example, a nurse describes her frustration with a relative of her patient who refused $B R C A 1 / B R C A 2$ testing:

"It was really hard to understand the perspective of the person who was refusing to be tested. This insurance would have covered it and it would not have cost them anything. They were more concerned about the fear of the future and were not open to listening to any other sides." (Nurse)

In some cases, the clinician's distress stemmed from not understanding the patient's decision. This was often associated with the provider questioning her performance either in terms of being able to adequately educate the family about the facts of the situation, to effectively partner with the patient, or to assist the patient in reaching the "right" decision. As a result, the clinician frequently felt inadequate, confused, or left out. Here, one clinical geneticist discussed a family who opted for fetal reduction of a twin pregnancy in which one twin was affected by a limb reduction anomaly:

"There was a woman I saw who had a twin pregnancy and the obstetricians had identified a reduction defect on one arm of one of the twins but the twins otherwise looked healthy. The day after I saw her, the OB called us back and said that the woman decided to do a selective reduction without amnio or without any further investigation, and that one really bothered me because I wondered if we had scared the woman, what was going on because I did not get that read from them at the office and it was totally out of the blue. Seemed to me that they had made this fairly significant decision without talking to us again or without really even bringing up the possibility in the counseling session." (Clinical geneticist)

When a patient is making a decision based on a poor understanding of information, or without wanting additional information, the clinician would often want to be directive and tell the patient what he or she should do. Some clinicians spoke of the patient making an "irrational" decision and experienced an internal battle over whether or not to challenge the patient. One clinical geneticist described the distress he experienced in needing to "hold back" when a family decided not to pursue enzyme replacement therapy for a child with Hurler syndrome:

"The conflict for all of us is that in trying to be nondirective, you are suppressing your own internal feelings about how strongly you would act had you been the parent in that you 
would act differently... It hurts you sometimes when you really think that we could have really done something for this child, but they did not want to . . . It kind of makes you feel like that you have failed them, because it is often hard to imagine why someone would make a different choice in these circumstances." (Clinical geneticist)

\section{Giving bad news ( $17 \%$ of total)}

The next most frequent type of situation associated with precipitating distress involved having to give bad news. Most of the time, the bad news concerned results or findings that are serious. Nearly all of the interviewees discussing these types of situations related that they felt somewhat inadequate and helpless and were distressed by feeling that they were inflicting harm on the patient. Here, a genetic counselor discusses preparing to tell a family that they have a second affected child with a fatal disorder:

"What I found really distressing, I guess for me personally, is knowing the impact that this would have on the family and knowing how devastated they would be and also feeling somewhat ill-equipped to deal with their loss and their bereavement." (Genetic counselor)

This same counselor talks about having to force herself to relay the news and to prepare for the aftermath:

"The most difficult part was actually having to say the words that the mutation results came back showing that he is at risk. I mean what was actually the hardest was to break the news to them because they were literally in that room holding their breath. You could just see how anxious they were and as the words came out it was complete devastation for them. It was very, very hard. I think, I guess, that was the hardest thing for me to actually get the words out and to tell them that." (Genetic counselor)

Occasionally, news was bad not because it involved a serious disorder, but because there was uncertainty related to the implications of the findings. One genetic counselor describes her feelings when she needed to help a couple make a decision based on mosaicism found on a chorionic villus sampling (CVS):

"When you cannot give them concrete information to go on, it is really difficult for them and it is difficult from a counseling point of view because they are looking to you for guidance of how to make the best decision they can. You just kind of feel helpless that no matter how much research you do you still cannot clarify the situation for them and they are looking to you for support and for information. You feel like you are not able to provide the most thorough information because it is not available. I guess feeling helpless is probably the biggest thing of just not being able to provide what they need." (Genetic counselor)

An obstetrician geneticist pointed out that uncertainty is particularly distressing when it involves a fetus:

"The gray area of trying to tell someone that there are some anomalies seen, that are not lethal anomalies all by themselves, but the baby may have something and I can't tell you what it may be. I can give you some guesses, but there is no way of knowing it and we may not know for a long, long time. Parents want to know, 'Is this baby going to be okay or not?' Then their decision-making process is, 'Well, do I abort or not abort?"' (Clinical geneticist)

These situations prompted the clinician to feel distress because he was not able to provide the information the patient needed to make a well-informed decision. The clinician would feel a tremendous burden of professional responsibility to help the patient but felt he could not, leading to distress.
One provider was distressed when she was "fired" by a family after giving them bad news. The distress resulted from feeling that her competence was being questioned even though she had done everything "by the books," and that her success in getting an answer quickly went unappreciated,

"We were able to make a diagnosis fairly quickly, within a week we were able to sit down with the family and give them a specific answer as to what was going on. The family reacted very hurt and upset despite us doing this exactly textbook on how you are suppose to give bad news, the family was still very upset and has not spoken to me since, fired me. In the room it was certainly sad to give the bad news. Afterward, to not only not be appreciated but be outright fired for reasons that remain unclear to me. I thought we did a great job of getting them an answer quickly and doing everything the way you are supposed to do it." (Clinical geneticist)

\section{Colleague behavior (15\%)}

Eight interviewees discussed distressing situations that were related to colleague behavior. During these episodes, the clinician frequently would feel abandoned or disrespected by the colleague, as experienced by this genetic counselor.

"The supervising physician who did the procedure had a very difficult time and made two attempts at CVS and both failed, no villi with pain. He came out of the room very flustered and bothered and went right past me, saying, 'It is a bad day.' $\mathrm{He}$ knew that she didn't have any villi and left me there to address it with the patient. The patient and her partner were very distraught and asked me, 'Well, why didn't Dr so and so tell us that and where do we go from here?' The physician just really abandoned the patient and abandoned me and left me there to try to help make it right for the patient. It was really distressing, really upsetting." (Genetic counselor)

In another situation that was distressing because of feeling that her expertise and opinion were being ignored by a physician, a nurse discussed a situation in which an adolescent patient exhibiting neurological symptoms was tested for Huntington disease despite the nurse's objections:

"I was really opposed to testing her and was quite vocal about that. The Neurogeneticist I work with disagreed and proceeded with the testing. I was asked to be a part of the team that gave her the test results and I have a lot of trouble with that . . .. I thought, Well, here we go again, the physician trumps the nurse! And I was reminded of the power in our health care system and the situation in most of these team kind of settings, uh, you have the M.D. at the head and you have the team. You may have many well-educated experienced individuals on the team, but ultimately the decision is made by the head of the team and everyone else is just dragged along." (Nurse)

In some of these instances, the interviewee was forced by a colleague to act outside of her comfort zone or to take on the burden of patient care for which she was not prepared. One genetic counselor spoke of a situation when she was a new genetic counselor and was asked by a colleague to spend time with a couple she did not know who were terminating a pregnancy because of a fetal anomaly:

"I felt totally unprepared and unable to do what I was being asked to do .... I was resentful of my supervisor for putting me in that position ..." (Genetic counselor)

\section{End of life (13\%)}

Seven interviewees were "kept up at night" by situations involving death and dying. Some of these situations involved the actual death of a patient while others involved the anticipated death. As would be expected, these situations precipitated 
feelings of sadness, such as this genetic counselor talking about patients with ovarian cancer:

"I have seen so many of these women pass away. These are amazing women that I have encountered over the years. That it is very hard to see . . I I have got tears in my eyes now thinking about it." (Genetic counselor)

Situations involving dying patients sometimes caused distress because the interviewee was unsure about how to act or about what kinds of emotions were appropriate given the professional involvement with the family. These emotions would provoke a feeling of inadequacy. Here, one genetic counselor talks about the death of a pediatric metabolic patient.

"It was emotionally distressing in that this was my first patient that passed away. I felt sadness and grief. I went to the funeral. It was really hard. I didn't realize how hard it would be. I guess I felt like in some way, I was a little bit inadequate, because this was the first death that I had experienced with a patient. So, I didn't know exactly how to react, especially at the funeral. I didn't realize that I would be so affected by it. I guess I felt a little bit uncomfortable and inadequate. I think next time I might try to distance myself a little bit more from it than I did this time." (Genetic counselor)

Several interviewees expressed concern that their own behavior at the time of a death might have made things more difficult for the family who was experiencing the loss. One genetic counselor who was trying to get a blood sample for a genetic test from a young dying girl suspected of having LiFraumini discussed questioning her actions:

"When I called the Mom, the little girl was more or less on her death bed and the mother did not think she was going to make it to the next day. Just having to talk to this woman who I had no previous relationship with and have to . . you know knowing that this woman is dealing with one of the hardest days of her life. Part of it was me worrying that I was not being sensitive enough." (Genetic counselor)

\section{Unintended outcomes (12\%)}

Interviewees also reported feeling distressed by situations with unintended outcomes. These situations included several instances of giving erroneous results, missing a diagnosis, or performing a procedure with an unintended outcome. These situations were accompanied by feelings of guilt, inadequacy, or helplessness. Here, a nurse discusses giving wrong results to a patient:

"We had a patient case where the physician got the test results and relayed that they were negative and the patient was actually positive. So I saw the patient assuming she was negative. I then had to turn around and call the patient and let her know that her test results were actually positive. That is a horrible, frightening experience to be incorrect especially with something of this magnitude. I just felt very sad for the patient. It was just very uncomfortable." (Nurse)

In another interview, an obstetrician geneticist described the distress she experiences when a woman has a miscarriage after she has performed a prenatal diagnostic procedure:

"When a patient loses a pregnancy after I have done a CVS or amniocentesis, it is just awful, because I know that the procedure caused the loss. That is an absolutely horrible feeling because you know you are responsible. I have shattered the dreams of this couple. I feel bad because they feel bad, so I am sort of empathizing with what they are going through and there is not much you can do to make them feel better. I feel bad because I ask myself questions like; did I do the procedure right? If they had gone to a different physician, would the same thing have happened?" (Clinical geneticist)

\section{Difficult patient (8\%)}

Situations involving difficult patients were also associated with unusual distress for several interviewees. Interviewees generally classified patients as difficult when they were demanding and unlikable. Distress occurred because the clinician felt guilty or inadequate in not being able to partner with the patient or was angry at the patient. Interviewees generally had good insight into why patients might be difficult, and they were sympathetic to what these patients were going through. Despite this, the patient's behavior led the clinician to dislike the patient and to then feel guilty for feeling that way and for not being able to develop a partnership with the patient. One genetic counselor described a situation with a difficult patient:

"I just found her a very difficult woman to like, because she was just so angry and treated her husband so badly. I felt like she was a miserable human being. I tried very hard to reach out to her and listen to her. I also feel like she came in on the defensive and I just couldn't get to her." (Genetic counselor)

Some of the distress was magnified by needing to provide services to these difficult patients over multiple encounters. One geneticist discussed the guilt she felt because she disliked a demanding mother with four mentally retarded children:

"It is one of those situations where she calls all the time. So, you are sort of wanting to avoid talking to her because when she gets on the phone, she goes on for an hour, and again, she's like 'what are you going to do to make it better for me?' I guess in some ways I feel a little guilty, as well, because I know how difficult it must be for this mom. That makes me feel guilty that I feel ill feelings toward her. I want to be able to help them but I know that I really am not going to be able to do anything. Again, I feel for this mom because I am a mom too. To see what she has to deal with is extremely difficult, but at the same time you are like 'get them off my back."' (Clinical geneticist)

Another genetic counselor was distressed by having to interact repeatedly with a difficult patient who came in for breast cancer risk assessment:

"She was an incredibly difficult person to deal with, just not a nice person at all. Then she ended up testing positive, which kind of made my life worse . . . For this lady, I didn't really feel bad that she was positive; I was just feeling bad because I knew she was going to be still just basically a pain in my butt. That isn't a good feeling. You don't really want to feel that way about a patient. I felt like, all I did was bend over backwards for her, you know, to be there for her, but it wasn't enough and at some point, the constant phone calls . . . it just became irritating. I would hear her voice and I would just be like 'Oh God.' I honestly hated her." (Genetic counselor)

\section{Injustice/inhumanity (8\%)}

Several of the interviewees discussed situations in which their distress was associated with injustice, resulting in not being able to obtain needed services for patients. The injustice related to lack of insurance or poor coverage for needed services. One nurse described her anger when a BRCA1/ $B R C A 2$ positive mutation carrier was denied coverage for a prophylactic mastectomy:

"She had no money for a prophylactic mastectomy. We were waiting for the Medicaid approval. Medicaid decided that she did not truly have a diagnosis and that they were not going to cover her. They said that until she gets cancer or if she would get pregnant, they would not cover her and there is really no way that she can get that surgery done because she cannot afford it. Our health care system is so messed up! I am angry that I probably will miss the chance to help someone." (Nurse) 
Two participants discussed distressing situations that provoked feelings of horror because of their inhumanity. In both of these situations, the interviewee discussed their disbelief that such situations could occur. In one interview, a clinical geneticist discussed the distress she experienced in viewing a severely malformed neonate:

"What happened was that there was a baby who was born who had the back of the head, the whole spine, everything was opened. I had just never seen such devastation to a human being, and it totally traumatized me . ... I think it exposed me to the possibility that the body could be distorted more than I had ever known ... That was a learning experience like wow! The body is not always going to look like a body. That was also frightening to realize that. It was probably twenty years ago and I still remember it." (Clinical geneticist)

In another interview, a genetic counselor discussed a patient who murdered her mentally retarded child:

"I think one of the distressing parts to me was just having been part of the system that was supposed to be supporting this family. I think there were some failures in that system that I think factor into her taking some desperate actions. Those are probably the biggest things. I mean just the reality that someone would kill their child is pretty tough." (Genetic counselor)

\section{DISCUSSION}

These genetics professionals could readily recall and discuss situations that were associated with high levels of distress, and, for the most part, were able to name and discuss the emotions they were experiencing during the distressing situation. Although the details of the situations involving clinician distress varied a great deal, the situations were easily categorized into seven different types. For each type of situation, the interviews enabled us to identify the types of distress that were commonly associated with it. The specific sorts of distress described by our interviewees are consistent with the eight subscales comprising the "clinician distress in patient care" scale that we developed through a previous survey of genetics professionals (some of whom participated in these interviews). ${ }^{1}$ That the sources of distress identified in these subscales - collegial distrust, personal values conflicts, compassion stress, the burden of professional responsibility, negative patient regard, inauthenticity; concerns about informational bias, and patient dread-are all reflected in the situations discussed by the clinicians interviewed, provides validation of the "clinician distress in patient care" scale.

In addition to describing specific situations that keep genetics professionals "up at night" and linking those situations with specific types of distress, the interviews enabled us to determine common emotional responses engendered in clinicians by each type of distress. These include a variety of emotions including anger, guilt, helplessness, and inadequacy.

In this study, anger often occurred in situations involving patient/family decision making or during encounters with difficult patients. Anger associated with decision-making situations typically arose when the clinician disapproved of the patient's values or their decision itself and could be compounded when the clinician, by taking a nondirective stance, chose not to challenge the patient's decision. Participants described having a personal opinion of what should be done and experienced distress when feeling compelled to support the "wrong" decision and to remain mute about their own opinion. The anger experienced could be directed at the patient or internally at the clinician him or herself. Anger is a common response to a conscious or unconscious threat to one's integrity, causing a particular type of suffering for the clinician. ${ }^{21}$

Our finding that clinicians experience distress resulting from a sense of obligation to be nondirective provides additional support to the notion that "nondirectiveness should be replaced as the guiding principle for the clinical practice and professional conceptualization of genetic counseling." 22 Nondirectiveness in fact inhibits the clinician from adopting psychosocial counseling approaches that ultimately enhance patient autonomy. ${ }^{23} \mathrm{We}$ have previously speculated that adherence to nondirectiveness interferes with the development of a partnership with the patient. ${ }^{24}$ Having a deep understanding of what the patient is experiencing can reduce anger and increase partnership, which is especially necessary in situations involving patient decision making, ${ }^{8}$ particularly decisions that should be based on the patient's personal values and personal preferences. ${ }^{25,26}$

Efforts should be made for the clinician to identify when he or she is feeling anger toward a patient because anger interferes with connecting emotionally with a patient and with being able to see things from the patient's perspective. ${ }^{7,27}$ If anger arises from a sense of judgment rather than inquiry, the relationship is likely to contract and become more rigid and unforgiving, ultimately undermining empathy. ${ }^{21}$

Feelings of guilt were surprisingly common among providers interviewed, and occurred in situations involving decision making, end of life, giving bad news, unintended outcomes, difficult patients, and social injustice. The guilt experienced in distressing situations involving difficult patients was often the result of another negative emotion experienced, such as disliking a patient or feeling disgusted by their reason for pursuing a course of action. Interviewees also talked about feeling guilty in situations when they thought they were adding to a patient's suffering or were unable to relieve the suffering. Although they recognized that the guilt experienced was unjustified, the strong and sometimes overinflated sense of responsibility for patients would result in feelings of guilt when things went wrong, which they often do in genetics.

Interviewees frequently mentioned feeling helpless and inadequate during situations involved giving bad news, decision making, or dealing with end-of-life issues. Giving bad news is recognized as difficult for most health care providers, even those with more experience. ${ }^{9}$ In our study, interviewees felt a tremendous responsibility to do it right so as to minimize harm. Distress occurred because the impact of the news could not be minimized, resulting in feelings of helplessness. ${ }^{28}$ Benoit et al. ${ }^{18}$ has pointed out that the general ability of genetic counselors (one groups of clinicians studied here) to connect empathetically and to feel a great sense of responsibility toward their patients leads them to compassion fatigue through absorbing their patient's suffering. Others have suggested that overidentification with patients through countertransference can lead to emotional distancing so as to protect the clinician from memories of past losses. ${ }^{29}$

Several providers discussed feeling inadequate during situations involving patient decision making. Much of the sense of inadequacy occurred when there was uncertainty about a diagnosis, recurrence risk, or management, or about how to help the patient make a decision. Despite the tremendous recent advances in genetic technology and the increase in the number of genetic tests available, genetic service providers are being called upon frequently to support patients making decisions about tests that provide uncertain information or to discuss therapies of unknown value. Most providers, however, are uncomfortable disclosing uncertainties because they fear that patients will lose confidence in them or that acknowledging un- 
certainty will paralyze further action. ${ }^{30}$ Gerrity et al. ${ }^{31}$ have shown that physicians experience anxiety and concern about bad outcomes when confronted with uncertainty in clinical practice. More recent evidence suggests that physicians are less likely to have affective stress reactions when faced with clinical uncertainty if their approach to patient care is more "holistic" than just biomedical. ${ }^{32}$

The emotional fallout of situations involving colleague behavior deserves special attention because of how frequently interviewees told stories of distress relating to colleague behavior. Although genetic service providers often work in a team comprising clinical geneticists, genetic counselors and, less frequently, nurses working in genetics, the nature of the teamwork, including the hierarchy and the roles and responsibilities of various genetic team members, has received little attention. The role of the nurse apropos to the physician in nongenetic medical care has received considerable attention, and it is the perceived lack of authority experienced by nurses that is the basis of their experience of moral distress. ${ }^{13,15,33}$ The feelings of anger, abandonment, and helplessness associated with situations involving colleague behavior are similar to the emotions characterizing a particular type of moral distress involving intraprofessional conflict. ${ }^{12,15}$ Several situations discussed by interviewees involved a time when he or she was caught "in the middle" between the physician and the patient or "holding the bag" when a colleague failed to take responsibility. In these instances, trust is broken because the implicit contract among colleagues to follow through on their commitments to each other is unfulfilled, leading to feelings of betrayal. ${ }^{34}$

Studies of emotions commonly experienced by clinicians in other specialties support our observations that anxiety, guilt, sadness, anger, and shame are often triggered by uncertainty, powerlessness, responsibility, lack of respect, and a difference in values. ${ }^{35}$ Although it may be difficult to reduce the occurrence of situations that might precipitate distress, genetics professionals' experience of distress could be mitigated by helping them to recognize the emotions that accompany the distress and address them when they occur. Moreover, genetics professionals may also benefit from cultivating greater resilience and enhancing their capacity to be with the emotions of their patients without being overwhelmed by them.

\section{Limitations}

The findings from this study need to be interpreted cautiously. Selection bias may have been present in response to the survey and again during the recruitment for the interview portion of the study. Genetics professionals who responded to the survey may have been more interested in the issue of distress, and those who agreed to be interviewed may have been more distressed or more willing to talk about it. Because nearly all nurses in genetics and genetic counselors are females, only 13 males were interviewed. Another limitation of this study is that those providers who were interviewed are currently seeing patients. We are therefore unable to determine if providers who are no longer seeing patients, possibly due to distress or burnout, experienced distress differently from those currently seeing patients. In addition, we report here on only one distressing situation discussed by participants. Although we asked them to choose and discuss one situation that they found to be especially distressing, it is possibly that other types of situations occur more frequently but are associated with less recalled distress.

\section{Implications for training and practice}

Despite the study's limitations, our findings allow us to make some recommendations for the training and practice of genetic service providers. These recommendations build on the recommendations we made previously based on results of our survey of distress in genetic service providers ${ }^{1,20}$ in which we recommended that (1) the distress experienced by genetic service providers must be acknowledged; (2) any group interventions to address distress should include all members of the genetics team; and (3) clinicians should seek ways to increase personal meaning derived from providing patient care by forming strong connections with patients through bearing witness to the events of their lives.

The findings from this qualitative study reaffirm these recommendations. Others have highlighted the importance of clinicians recognizing and accepting the emotions experienced in the course of providing patient care..$^{3,8,35,36}$ Unless feelings are identified and accepted as normal, maladaptive behaviors are likely to follow that will interfere with the clinician being able to provide high quality and compassionate care that meets the needs and goals of both the patient and the clinician. $^{3}$ The clinician therefore needs to become self-aware by reflecting on experienced emotions, examining belief systems and values, and understanding the connection between the emotions and behavior. Self-awareness allows the clinician to attend to the needs of the patient, the work environment, and his or her interactions with the patient. ${ }^{7}$ This self-reflection depends on the presence of mindfulness in which the clinician engages in self-monitoring, is open to new knowledge and perspectives, and adopts a sense of curiosity about the lives and experiences of patients. ${ }^{28}$ By doing so, uncertainty can be welcomed rather than avoided, and difficult patients might become interesting patients. ${ }^{7}$ Clinicians who are more self-aware will experience more job satisfaction, less stress, and experience empathy as a mutually healing connection with patients. ${ }^{7}$ Strategies to enhance self-awareness can also provide a foundation for cultivating one's resilience to navigate challenging and distressing situations that arise in genetics practice.

A variety of ways to become more self-aware have been tested, including mindfulness meditation ${ }^{37,38}$ and reflective writing. ${ }^{39,40}$ Mindfulness, the cultivation of mental and emotional stability, promotes calm and resilience and helps to reduce reactivity to self and others. It can be particularly useful in situations that cause distress associated with feelings of anger, helplessness, and despair. ${ }^{41}$ Mindfulness is an antidote to clinicians taking on the suffering of their patients and being overwhelmed by their own emotions. Training in mindful meditation has been shown to reduce depression and anxiety and increase empathy in medical students. ${ }^{42}$ In a study of nursing students, mindful meditation training reduced students' anxiety, promoted a greater sense of well-being, and improved coping skills. In a recent study of primary care physicians, Krasner et al. ${ }^{43}$ showed that participating in an educational program in mindfulness, communication, and self-awareness was associated with improvements in burnout, mood disturbance, and empathy. In addition, the training was associated with greater resilience and a more patient-centered approach to patient care.

Reflective writing may involve writing a brief narrative about a specific patient care experience, with a focus on the clinician reacting to the situation and then sharing it and working with a group of colleagues. ${ }^{44}$ Reflective writing may promote clinician well-being through increased emotional equilibrium, self-healing, and building community while reducing isolation. ${ }^{45}$ Reflective writing workshops have provided clinicians with an opportunity to reflect deeply in an environment of mutual support on the personal meaning of their work. ${ }^{46}$

Reflecting on emotions associated with distress experienced in patient care may also be facilitated through one-on-one 
consultation with a colleague or mentor, or through a formal or informal group meeting with colleagues or through peer supervision. ${ }^{47-50}$ Rushton ${ }^{13}$ has outlined a variety of recommendations for addressing distress in the nursing profession that are highly relevant for genetic service providers. These include recognizing symptoms of distress, using interdisciplinary forums to systematically review difficult cases including why they happened, and exploration and implementation of interventions to address the root causes of distress. Peer support groups for genetic counselors are becoming increasingly common and can provide a venue for the sharing of feelings and experiences and a safe setting for counselors to process their emotions related to distressing patient care experiences. ${ }^{51}$ Although we are not aware of programs that offer group interventions including members of the genetics health care team in addition to genetic counselors, support groups including multidisciplinary teams in other settings such as oncology have successfully met the emotional needs of various groups members and increased the well-being of team members. ${ }^{52-55}$

Because of the prevalence of distress associated with colleague behavior, we recommend that group interventions or meetings should include all members of the genetic service team. The sessions should create a safe environment and allow each team member to be heard and acknowledged, and promote discussion and clarification of the role of individual team members.

Given the prevalence of distress associated with situations involving patient/family decision making, giving bad news, and death and dying, additional communication skill-based training is likely to be beneficial to most genetic service providers. Both clinician training in delivering bad news and creating opportunities for clinicians to process their own grief have been associated with reduced burnout. ${ }^{56}$ Physicians in particular report little formal training in communication skills targeted to guiding family decision making or to eliciting patients' goals and values. ${ }^{57}$ Although specific training for genetic service providers in communication relating to breaking bad news has been advocated, ${ }^{58}$ based on our interviews, additional training is warranted. Learner-centered programs for clinicians aimed at improving communication skills are available that include a cognitive component, a behavioral component involving opportunities for role playing, and an affective component centered on an exploration of the feelings associated with communication about difficult issues. ${ }^{9,54}$ Additionally, methods of training that include attention to developing awareness of maintaining a stance of "learner" rather than "judger" during patient/family encounters may also be useful in building clinician competence and confidence in navigating difficult conversations. ${ }^{21}$

Self-awareness can help clinicians to connect with what is meaningful to them in their work with patients. ${ }^{59}$ Remen $^{36}$ has argued that distress, suffering, and burnout among health care providers result from loss of meaning, commitment, and service that attracted these individuals to the healing profession in the first place. In other areas of clinical practice such as palliative care, meaning making is seen as an antidote to helplessness, despair, and suffering for patients, families, and clinicians. In these settings, routine opportunities to reflect on what caring for a patient has taught them and the meaning of their work with dying people can be supportive to the well-being of clinicians. ${ }^{60}$ Remen $^{36}$ emphasizes the importance of meaning as not only a way to reduce clinician distress and suffering but also a means to become more effective in patient care. Efforts among genetic service providers to address and reduce distress and to increase the meaning derived from providing patient care are needed so as to ensure an emotionally healthy genetics workforce that is prepared to provide compassionate care to their patients and reaffirm their commitment to their profession.

\section{ACKNOWLEDGMENTS}

This study is supported by Grant no. 5R01HG3004-2 from the National Human Genome Research Institute. We thank the genetics professionals who responded to our survey and participated in the interviews. We also appreciate the contributions of the other members of our study team and the logistical assistance of the leadership of the National Society of Genetic Counselors, the International Society of Nurses in Genetics, the American Board of Medical Genetics, and the American Society of Human Genetics.

\section{REFERENCES}

1. Bernhardt BA, Rushton CH, Carrese J, Pyeritz RE, Kolodner K, Geller G. Distress and burnout among genetic service providers. Gen Med 2009;11: 527-535.

2. Oehler JM, Davidson MG. Job stress and burnout in acute and nonacute pediatric nurses. Am J Crit Care 1992;1:81-90.

3. Meier DE, Back AL, Morrison RS. The inner life of physicians and care of the seriously ill. JAMA 2001;286:3007-3014.

4. Kash KM, Holland JC, Breitbart W, et al. Stress and burnout in oncology. Oncology (Williston Park) 2000;14:1621-1633.

5. Geller G, Rushton CH, Carrese J, Kolodner K, Bernhardt BA. Genetic professionals' experiences with grief and loss: implications for support and training. Clin Genet In press.

6. French SE, Lenton R, Walters V, Eyles J. An empirical evaluation of an expanded nursing stress scale. J Nurs Meas 2000;8:161-178.

7. Kearney MK, Weininger RB, Vachon MLS, Harrison RL, Mount BM. Self-care of physicians caring for patients at the end of life: "being connected .... a key to my survival." JAMA 2009;301:1155-1164.

8. Strous RD, Ulman A-, Kotler M. The hateful patient revisited: relevance for 21st century medicine. Eur J Intern Med 2006;17:387-393.

9. Fallowfield L, Jenkins V. Communicating sad, bad, and difficult news in medicine. Lancet 2004;363:312-319.

10. Ulrich CM, Hamric AB, Grady C. Moral distress: a growing problem in the health professions? Hastings Cent Rep 2010;40:20-22.

11. Jameton A. Nursing practice: the ethical issues. Englewood Cliffs, NJ: Prentice-Hall, 1984.

12. Corley MC. Nurse moral distress: a proposed theory and research agenda. Nurs Ethics 2002;9:161-178.

13. Rushton $\mathrm{CH}$. Defining and addressing moral distress: tools for critical care nursing leaders. AACN Adv Crit Care 2006;17:161-168.

14. McCarthy J, Deady R. Moral distress reconsidered. Nurs Ethics 2008;15: $254-262$.

15. Hamric AB, Davis WS, Childress MD. Moral distress in health care professionals: what is it and what can we do about it? Pharos Alpha Omega Alpha Honor Med Soc 2006;69:16-23.

16. Figley C. Compassion fatigue. New York: Brunner/Mazel, 2005.

17. Meadors $\mathrm{P}$, Lamson A. Compassion fatigue and secondary traumatization: provider self care on intensive care units for children. J Pediatr Health Care 2008;22:24-34.

18. Benoit LG, Veach PM, LeRoy BS. When you care enough to do your very best: genetic counselor experiences of compassion fatigue. J Genet Couns 2007; 16:299-312.

19. Kessler S. Psychological aspects of genetic counseling. VIII. Suffering and countertransference. J Genet Counsel 1992;1:303-308

20. Geller G, Bernhardt BA, Carrese J, Rushton CH, Kolodner K. What do clinicians derive from partnering with their patients? A reliable and valid measure of "personal meaning in patient care." Patient Educ Couns 2008; 72:293-300

21. Rushton $\mathrm{CH}$, Adams $\mathrm{M}$. Asking ourselves and others the right questions: a vehicle for understanding, resolving, and preventing conflicts between clinicians and patients and families. AACN Adv Crit Care 2009;20:295-300.

22. Weil J. Psychosocial genetic counseling in the post-nondirective era: a point of view. J Genet Couns 2003;12:199-211.

23. Weil J, Ormond K, Peters J, Peters K, Biesecker BB, LeRoy B. The relationship of nondirectiveness to genetic counseling: report of a workshop at the 2003 NSGC Annual Education Conference. J Genet Couns 2006;15:85-93.

24. Bernhardt BA, Geller G, Doksum T, Metz SA. Evaluation of nurses and genetic counselors as providers of education about breast cancer susceptibility testing. Oncol Nurs Forum 2000;27:33-39.

25. Geller G, Strauss M, Bernhardt BA, Holtzman NA. "Decoding" informed consent. Insights from women regarding breast cancer susceptibility testing. Hastings Cent Rep 1997;27:28-33. 
26. Whitney SN, McGuire AL, McCullough LB. A typology of shared decision making, informed consent, and simple consent. Ann Intern Med 2004;140: 54-59.

27. Halpern J. Empathy and patient-physician conflicts. $J$ Gen Intern Med 2007;22:696-700.

28. Geller G. A "holistic" model of the healing relationship: What would that require of physicians? Am J Bioethics 2006;6:82-85.

29. Weil J. Psychosocial genetic counseling. New York: Oxford University Press, Inc., 2000.

30. Katz J. The silent world of doctor and patient. Baltimore: Johns Hopkins University Press, 1984

31. Gerrity MS, DeVellis RF, Earp JA. Physicians' reactions to uncertainty in patient care. A new measure and new insights. Med Care 1990;28:724-736.

32. Evans L, Trotter DRM. Epistemology and uncertainty in primary care: an exploratory study. Fam Med 2009;41:319-326.

33. Pendry PS. Moral distress: recognizing it to retain nurses. Nurs Econ 2007;25:217-221.

34. Reina ML, Reina DS, Rushton CH. Trust: the foundation for team collaboration and healthy work environments. AACN Adv Crit Care 2007;18:103108 .

35. Kasman DL, Fryer-Edwards K, Braddock CH III. Educating for professionalism: trainees' emotional experiences on IM and pediatrics inpatient wards. Acad Med 2003;78:730-741.

36. Remen RN. Recapturing the soul of medicine: physicians need to reclaim meaning in their working lives. West J Med 2001;174:4-5.

37. Epstein RM. Mindful practice. JAMA 1999;282:833-839.

38. Kabat-Zinn J. Mindfulness-based interventions in context: past, present, and future. Clin Psychol Sci Pract 2003:10:144-156.

39. Charon R. Narrative medicine: honoring the stories of illness. New York: Oxford, 2008 .

40. Charon R. Narrative medicine: a model for empathy, reflection, profession, and trust. JAMA 2001;286:1897-1902.

41. Rushton CH, Sellers DE, Heller KS, Spring B, Dossey BM, Halifax J. Impact of a contemplative end-of-life training program: being with dying. Palliat Support Care 2009;7:405-414.

42. Shapiro SL, Schwartz GE, Bonner G. Effects of mindfulness-based stress reduction on medical and premedical students. J Behav Med 1998;21:581599.

43. Krasner MS, Epstein RM, Beckman H, et al. Association of an educational program in mindful communication with burnout, empathy, and attitudes among primary care physicians. JAMA 2009;302:1284-1293.

44. Rabow MW. Doctoring to heal: fostering well-being among physicians through personal reflection. West J Med 2001;174:66-69.
45. Shapiro J, Kasman D, Shafer A. Words and wards: a model of reflective writing and its uses in medical education. J Med Humanit 2006;27:231-244.

46. Horowitz CR, Suchman AL, Branch WT, Frankel RM. What do doctors find meaningful about their work? Ann Intern Med 2003;138:772-775.

47. Wallace JE, Lemaire J. On physician well being-you'll get by with a little help from your friends. Soc Sci Med 2007;64:2565-2577.

48. Maytum JC, Heiman MB, Garwick AW. Compassion fatigue and burnout in nurses who work with children with chronic conditions and their families. J Pediatr Health Care 2004;18:171-179.

49. Kennedy AL. A leader-led supervision group as a model for practicing genetic counselors. J Genet Couns 2000;9:391-397.

50. Kjeldmand D, Holmström I, Rosenqvist U. Balint training makes GPs thrive better in their job. Patient Educ Couns 2004;55:230-235.

51. Zahm KW, McCarthy Veach P, LeRoy BS. An investigation of genetic counselor experiences in peer group supervision. $J$ Genet Couns 2008;17: $220-233$.

52. Le Blanc PM, Hox JJ, Schaufeli WB, Taris TW, Peeters MCW. Take care The evaluation of a team-based burnout intervention program for oncology care providers. J Appl Psychol 2007;92:213-227.

53. Penson RT, Kyriakou H, Zuckerman D, Chabner BA, Lynch TJ Jr. Teams. Communication in multidisciplinary care. Oncologist 2006;11:520-526.

54. Back AL, Arnold RM, Baile WF, Tulsky JA, Fryer-Edwards K. What makes education in communication transformative? J Cancer Educ 2009;24:160 162

55. Rushton CH, Reder E, Hall B, Comello K, Sellers DE, Hutton N. Interdisciplinary interventions to improve pediatric palliative care and reduce health care professional suffering. J Palliat Med 2006;9:922-933.

56. Shanafelt TD, Novotny P, Johnson ME, et al. The well-being and personal wellness promotion strategies of medical oncologists in the North Central Cancer Treatment Group. Oncology 2005;68:23-32.

57. Boss RD, Hutton N, Donohue PK, Arnold RM. Neonatologist training to guide family decision making for critically ill infants. Arch Pediatr Adolesc Med 2009;163:783-788.

58. Dent KM, Carey JC. Breaking difficult news in a newborn setting: down syndrome as a paradigm. Am J Med Genet Part C Semin Med Genet 2006;142:173-179.

59. Shanafelt TD. Enhancing meaning in work: a prescription for preventing physician burnout and promoting patient-centered care. JAMA 2009;302: 1338-1340.

60. Keene E, Hutton N, Hall B, Rushton C. Bereavement debriefing sessions: an interdisciplinary intervention to support health care professionals in managing their grief after the death of a patient. Pediatr Nurs In press. 